\title{
Cultura política, ideologia e comportamento eleitoral: alguns apontamentos teóricos sobre o caso brasileiro
}

\author{
Julian Borba \\ Universidade do Vale do Itajaí
}

\begin{abstract}
Resumo
Este artigo trata das inter-relações entre os conceitos de cultura política, ideologia e comportamento eleitoral na busca da compreensão do chamado "eleitor brasileiro" através da apresentação de algumas vertentes explicativas. São definidos os conceitos de cultura política e ideologia, além da apresentação das principais teorias do comportamento eleitoral e das tipologias do voto no Brasil. O estudo conclui por um eleitor de tipo personalista, o qual decide seu voto, principalmente, a partir dos atributos individuais, de competência e honestidade dos candidatos. Por fim, busca-se uma explicação de origem histórica para esse padrão de comportamento eleitoral.
\end{abstract}

Palavras-chave: cultura política, ideologia, comportamento eleitoral, Brasil.

\section{Abstract}

This article analyses the interrelations between the concepts of political culture, ideology and voting behavior, in an attempt to understand the so-called "Brazilian voter". It defines the concepts of political culture and ideology, and presents the principal theories of electoral behavior and the typologies of the vote in Brazil. It concludes by giving a typology of the Brazilian voter, who is defined as personalist. oriented, deciding his vote principally on this basis of the individual attributes, competence and honesty of the candidates. Finally, it seeks to explain the historical origin of this behavioral pattern among voters. Key words: political culture, ideology, voting behavior, Brazil. 


\section{Introdução}

Um dos campos de análise mais desenvolvidos na ciência política contemporânea é a análise do comportamento eleitoral. Diferentes autores têm proposto alternativas teórico-metodológicas para explicar a forma como os cidadãos se comportam perante os fenômenos do "mundo político" e, mais especificamente, como decidem seu voto. Neste artigo, fazemos uma incursão nesse debate, focalizando a relação entre os conceitos de cultura política, ideologia e comportamento eleitoral e estabelecemos alguns padrões para a compreensão do chamado "eleitor brasileiro".

O texto está dividido em quatro partes: na primeira, definimos o conceito de cultura política a partir da matriz estabelecida por Almond e Verba (1989) e seus desenvolvimentos posteriores. Em seguida, trabalhamos com o conceito de ideologia e sua relação com a cultura política. São estabelecidas aí as diferenciações entre "ideologia primária" e "ideologia secundária". Na terceira parte, são focalizadas as teorias do comportamento eleitoral e as principais tipologias explicativas para o eleitor brasileiro. Por fim, nas considerações finais, construímos uma tipologia própria para a compreensão do eleitor brasileiro, a partir das relações estabelecidas entre os conceitos de cultura política e ideologia.

\section{O conceito de cultura política}

Partimos do suposto de que o conceito de cultura política estabeleceu uma área de conhecimento da ciência política a partir do clássico livro de Gabriel Almond e Sidney Verba (1963 [1989]), The civic culture: political attitudes and democracy in five countries ${ }^{1}$.

Na forma como foi pensado pelos autores, esse conceito assumia um forte viés normativo. A preocupação estava, sobretudo, com a estabilidade democrática e as condições culturais para o estabelecimento da democracia "[...] entendida como - sistema político norte-americano, em contraposição ao socialismo soviético" (CASTRO, 2000, p. 17). Deste modo, as análises procuravam responder a uma

\footnotetext{
${ }^{1}$ Isto não significa que a preocupação com a cultura política não estivesse presente nos estudos políticos anteriores a Almond \& Verba. Como destaca Baquero "embora já estivessem presentes, no horizonte da política clássica desde os estudos de Platão, Aristóteles e Sócrates a preocupação com a capacidade política dos cidadãos e o seu papel na sociedade, os debates que surgem na década mencionada começam a ser pautados por uma nova perspectiva de análise, e possibilita o surgimento de uma nova área de estudo, qual seja, a da política comparada empírica" (BAQUERO, 2001, p. 4). Castro (2000) também destaca que o que diferencia "os estudos dos últimos 30 ou 40 anos dos anteriores, (...) não é o tema, mas a abordagem teórica, e acima de tudo, o instrumental metodológico" (CASTRO, 2000, p. 20). Para uma genealogia do conceito de cultura política, Almond (1980).
} 
BORBA, J. Cultura política, ideologia e comportamento eleitoral:...

dupla demanda: "por um lado, reforçar e justificar a compreensão da supremacia da sociedade norte-americana como modelo a ser seguido; por outro, promover e justificar a política norte-americana [...]" (CASTRO, 2000, p. 17).

Em The civic culture, o conceito de cultura política estava delimitado às atitudes e orientações dos cidadãos em relação aos assuntos políticos: "O termo 'cultura política' refere-se às orientações especificamente políticas, às atitudes com respeito ao sistema político, suas diversas partes e o papel dos cidadãos na vida pública" (ALMOND e VERBA, 1989, p. 12). Através desse conceito, visava-se chegar à caracterização daquilo que seria a cultura política de uma nação, definida como “[...] a distribuição particular de padrões de orientação política com respeito a objetos políticos entre os membros da nação" (ALMOND e VERBA, 1989, p. 13), bem como afastar-se das explicações mais em voga da ciência política de sua época, marcadas por uma forte ênfase no estudo das instituições políticas, que ainda não haviam conseguido desvencilhar-se das origens judicialistas da disciplina.

Os autores distinguem três tipos de orientação política: 1) a "orientação cognitiva", que significa o conhecimento do sistema político e a crença nele, nos seus papéis e nos seus titulares, seus inputs e outputs; 2) a "orientação afetiva", que se traduz pelos sentimentos sobre o sistema político, seus papéis, pessoas e desempenho; e 3) "a orientação avaliativa", significando o julgamento e as opiniões sobre os objetos políticos, que tipicamente envolvem a combinação de padrões de valor, bem como de critérios de valor com informações e sentimentos (ALMOND e VERBA, 1989, p. 14).

Tais orientações seriam avaliadas a partir de diferentes classes de objetos políticos, que iriam desde sentimentos mais genéricos, passando por processos políticos e administrativos, chegando até o papel do indivíduo. Do cruzamento entre as orientações com as classes de objetos políticos, resultariam três diferentes tipos de cultura política: a paroquial, a súdita e a participante.

Esta diferenciação deu base para o aspecto mais polêmico de sua obra, ou seja, uma relação de causalidade entre cultura e estrutura políticas da qual derivou que a existência de uma democracia estável em determinada sociedade estaria condicionada pela sustentação de uma cultura cívica:

“[...] em geral, culturas paroquial, súdita ou participante seriam mais congruentes, respectivamente, com uma estrutura política tradicional, com uma estrutura autoritária centralizada e com uma estrutura política democrática" (ALMOND e VERBA, 1989, p. 20). 
A principal e mais sistemática crítica à tradição de estudos da cultura política aponta que por trás do conceito de Almond e Verba, haveria um determinismo culturalista implícito nas hipóteses originais do estudo². Cultura política está entendida em The civic culture como uma variável independente de qualquer outro fator, em uma opção metodológica com conseqüências extremamente problemáticas, pois, como afirma Moisés, implicaria tratar a cultura política "[...] como um deus ex machina, isto é, como se a existência de valores políticos pudesse ocorrer sem a necessidade de identificarem-se as suas causas" (MOISÉS, 1995, p. 93) . $^{3}$

Pensa-se que a melhor maneira de sair desse determinismo culturalista não está no apelo a outros determinismos, tal como têm feito algumas abordagens institucionalistas que, sob o pretexto de não reificar a cultura política, acabam atribuindo às instituições um caráter determinante na configuração de processos políticos ${ }^{4}$. Concorda-se com Moisés quando afirma que:

“[...] processos clássicos de democratização sugerem que, mesmo admitindo-se a existência de certa margem de autonomia na sua formação, valores, atitudes e procedimentos políticos se reforçam a partir da interação entre o comportamento e o funcionamento das instituições políticas, algo que implica tanto em processos de aprendizagem do seu uso, como de ressocialização política induzida pela experiência, mas ambos sedimentam-se com o passar do tempo e com a continuidade dos processos que constituem os sistemas políticos" (MOISÉS, 1995, p. 94$)^{5}$.

Nesse sentido, com base nos trabalhos de Inglehart (1988; 2002), Putnam (1996) e Pharr e Putnam (2000), defende-se uma abordagem para o estudo da cultura política que sirva como instrumental analítico para pesquisar as crenças, os valores e identidades dos diferentes grupos existentes na sociedade.

\footnotetext{
2 Para uma visualização das principais críticas ao conceito de cultura política, remete-se aos trabalhos de Street (1993), Castro (2000), Moisés (1995), Rennó (1998), Badie e Hermet (1993), Chilcote (1998) e Diamond (1994).

3 Segundo Castro (2000, p. 77), o maior erro da abordagem almondiana está na afirmação de que a cultura política encontrada na Inglaterra e Estados Unidos é o tipo de cultura democrática.

${ }^{4}$ Para uma típica visão "hiperinstitucionalista", ver Przeworski et al. (2003).

${ }^{5}$ As interfaces entre instituições e cultura política no processo de democratização têm sido exploradas no Brasil através dos trabalhos de Paulo Krischke. Ver Krischke (1997).
} 
BORBA, J. Cultura política, ideologia e comportamento eleitoral:...

Na mesma direção, Lane (1992) propõe o uso da categoria de cultura política não como um esquema classificatório, "[...] mas como um método de análise de certo grupo, tentando articular um modelo de interpretação da sua rede de crenças" (RENNÓ, 1998, p. 86).

Assim, o objetivo das análises de cultura política - e é aí que se insere a presente análise - é contribuir para a explicação do comportamento político dos indivíduos, destacando a forma como os valores culturais são componentes endógenos da tomada de decisão.

\title{
Cultura política e ideologia
}

As considerações sobre cultura política e ideologia ${ }^{6}$ dizem respeito aos possíveis impactos das construções ideológicas sobre a cultura política de uma sociedade. Uma abordagem nessa direção foi realizada por Debrun (1983 e 1989) através da diferenciação entre ideologia primária e ideologia secundária. Debrun afirma inicialmente que o quase silêncio das ciências sociais diante dos mecanismos ideológicos possui duas explicações básicas: a primeira é a "[...] aparente evidência de que a ideologia da classe dominante é, por definição, a ideologia dominante e que, nessa base, impõem-se sem dificuldade os mitos que iludem os dominados" (DEBRUN, 1989, p. 172). Desta maneira, ficam esquecidas

\begin{abstract}
"[...] a edificação das estruturas argumentativas, sua contaminação maior ou menor pelos procedimentos retóricos (metáfora e metonímia em particular), suas barganhas implícitas com as ideologias prévias dos grupos dominados ou que se trata de dominar. É através dessa elaboração, no entanto, que o que era tão-somente um esboço se transforma, simultaneamente, em ideologia dominante e ideologia da classe dominante, ao mesmo tempo em que se estabelece ou consolida a própria dominação econômica, política e cultural" (DEBRUN, 1989, p. 173).
\end{abstract}

A segunda explicação refere-se à maciça utilização, no campo teórico, de temáticas marxistas ou estruturalistas, que retiram do ator social a tarefa de produção de ideologias, inclusive a ocultação ideológica.

\footnotetext{
${ }^{6} \mathrm{O}$ conceito de ideologia é aqui entendido em sua acepção crítica, de inspiração marxista. Entende-se por tal conceito, toda forma de construção simbólica que visa estabelecer ou manter relações de dominação (THOMPSOM, 1995).
} 
Para o autor, uma alternativa a tais visões seria a idéia de que o ator não forja as ideologias a partir do nada, mas alicerçando-se num referencial, que denomina de "ideologia primária", que corresponderia à cultura política de um determinado grupo, ou seja, o conjunto de atitudes e orientações dos cidadãos em relação aos fenômenos políticos. A produção de ideologias seria "[...] então uma ideologia “secundária'” (DEBRUN, 1989, p. 175). "A operação de ocultação ideológica seria então não um trabalho 'ideologia sobre o fato', mas 'ideologia sobre ideologia'” (DEBRUN, 1989, p. 181). Percebe-se aqui uma relação dialética entre a produção de ideologias e a cultura política de uma sociedade. As ideologias são formuladas a partir de um referencial simbólico (cultura política) compartilhado pelos indivíduos de uma sociedade, que lhe dá condições de operação. Ao mesmo tempo, a ideologia age no sentido de alterar esse referencial simbólico, de acordo com o tipo de dominação que pretenda estabelecer.

Assim, as ideologias primárias seriam aquelas engendradas “[...] na práxis imediata dos atores, particularmente a dos atores dominantes" (DEBRUN, 1983, p. 19). E o essencial, segundo Debrun, é o seu desvendamento por duas razões principais: primeiro, porque as estratégias de base têm sido, em geral, eficientes, independentemente de uma formulação explícita e sistemática e, portanto, da obra dos grandes ideólogos. A segunda razão da ênfase sobre a ideologia "primária" seria pelo fato de que a ideologia secundária, longe de representar a essência da ideologia, só se desenvolve quando surgem ameaças para o predomínio de determinada ideologia primária.

Isto foi o que ocorreu na década de 1930 no Brasil, quando fórmulas novas, como o fascismo e o comunismo, começaram a ameaçar a "ordem". "A função da ideologia 'secundária' é então abafar as dúvidas que começam a invadir os portadores da ideologia 'primária', o que implica que essa ideologia saia do silêncio, na sua evidência para se transformar numa construção mais elaborada". 0 traço mais pertinente dessa ideologia secundária consiste num esforço de fundamentação: “[...] trata-se, para ela, de fundamentar o que se 'constata' em nível primário. Invoca, por exemplo, a mistura racial como fundamento da 'cordialidade' brasileira [...]” (DEBRUN, 1983, p. 20). 
Segundo o autor, o maior exemplo de ideologia primária no Brasil teria sido a chamada estratégia da "conciliação", já materializada na cultura política da sociedade brasileira ${ }^{7}$. Debrun focaliza, sobretudo, a conciliação em nível político, "[...] a qual está concebida como um acordo entre atores - grupos ou indivíduos de um peso mais ou menos igual. Ou, pelo menos, nenhum dos dois poderia esmagar o outro". A idéia "brasileira" de conciliação "[...] sempre pressupôs o desequilíbrio, a dissimetria dos parceiros, e não seu equilíbrio". Ela serviu sempre para "[...] formalizar e regular a relação entre atores desiguais, uns já dominantes e os outros já dominados. E para permitir que os primeiros explorassem em seu proveito a transformação dos segundos em sócios caudatários" (DEBRUN, 1983, p. 15):

\begin{abstract}
"Depois de ter sido enaltecido por Nabuco de Araújo, nos primórdios da década de cinqüenta do século passado, quando ele oferecia uma 'ponte de ouro' aos liberais vencidos da Revolução Praieira, a 'conciliação' entrou depois num quase silêncio por mais de meio século. Havia um discurso da 'conciliação', legível entre as linhas no coronelismo ou na 'política dos governadores' de Campos Salles. Mas esse discurso era o mais das vezes implícito. Limitava-se a afirmar, em atos, mais do que em palavras, a 'índole pacífica de nossa gente'. Mesmo porque a política da 'conciliação', não encontrando resistências ponderáveis, era como que verificada nos fatos. O que permitiu por sua vez ao discurso liberal continuar dominando o espaço político verbal, na falta de contendores" (DEBRUN, 1983, p. 19).
\end{abstract}

Ainda nesse texto, o autor já dava algumas pistas de como a economia teria se transformado numa ideologia primária: "[...] o significado principal do neodesenvolvimentismo é este: político e ideológico, mais do que econômico. Ou melhor, a economia se transformou na ideologia da política, as infra e as superestruturas trocaram momentaneamente seus papéis" (DEBRUN, 1983, p. 37, grifo do autor).

\footnotetext{
7 Debrun inicia a introdução de seu livro afirmando que os traços gerais da política brasileira nunca se alteraram desde a Independência. "Face à grande diversidade de conjunturas, as forças dominantes reagiram lançando mão de um número limitado de estratégias políticas, sempre as mesmas. Situação essa que permanece ainda hoje, em que pesem os arranhões que vêm sofrendo de modo crescente. Daí a repetição, cansativa de certos temas: essa monotonia temática procura ser a imagem temática de uma realidade política vista, senão como estagnada, como capaz de uma reprodução indefinida, mediante o uso de alguns mecanismos seculares de dominação que, até o momento, se revezaram no palco do poder" (DEBRUN, 1983, p. 13).
} 
Dessas análises se depreende que a ideologia possui dois grandes momentos de operação: o momento primário, quando está materializada, cristalizada ou naturalizada nas relações sociais, e o momento secundário, que surge quando as ideologias primárias estão em crise e aparecem com a função de fundamentação ou racionalização de idéias que objetivam criar ou manter determinadas formas de dominação.

A apropriação que Zizek (1996) faz da abordagem de Hegel aproxima-se desta diferenciação entre ideologia primária e secundária, porém é muito mais rica analiticamente. Segundo Zizek, Hegel distinguiu três grandes momentos da religião: doutrina, crença e ritual. Essa diferenciação permitiria distribuir a operação da ideologia em torno de três grandes momentos: (1) ideologia como um complexo de idéias (teorias, convicções, crenças, métodos de argumentação); (2) a ideologia em seu aspecto externo, ou seja, a materialidade da ideologia, os aparelhos ideológicos de Estado; (3) e, por fim, o campo mais fugidio, a ideologia "espontânea" que atua no cerne da própria "realidade" social (ZIZEK, 1996).

Estes momentos poderiam, aqui, também se associar ao conceito de cultura política. O primeiro seria aquele da noção de ideologia como doutrina "[...] destinada a nos convencer de sua 'veracidade', mas, na verdade, servindo a algum inconfesso interesse particular de poder" (ZIZEK, 1996, p. 15).

No segundo momento de manifestação do fenômeno ideológico, encontra-se a ideologia em sua "alteridade-externalização" (ZIZEK, 1996). Este momento, segundo Zizek, estaria materializado na noção althusseriana de Aparelhos Ideológicos de Estado (AIE), que aponta para a existência da ideologia nas instituições e nos rituais ideológicos. Como exemplifica Althusser, "[...] a fé religiosa, por exemplo, não é apenas nem primordialmente uma convicção interna, mas é a Igreja como instituição e seus rituais, os quais, longe de serem uma simples externalização secundária, representam os próprios mecanismos que a geram" (ZIZEK, 1996, p. 18, grifo no original). O que se encontra nesse momento de manifestação "[...] é a regressão para a ideologia no exato ponto em que parecemos estar saindo dela" (ZIZEK, 1996, p. 18).

O terceiro momento da ideologia não seria nem sua expressão como doutrina explícita, como convicções articuladas sobre a natureza do homem, da sociedade e do universo, nem sua existência material (as instituições, os rituais e práticas que Ihe dão corpo), mas sim sua forma "espontânea", naturalizada nas práticas e relações sociais. Nas palavras de Zizek:

"[...] a rede elusiva de pressupostos e atitudes implícitos, quase 'espontâneos', que formam um momento irredutível de reprodução de práticas 'não ideológicas' (econômicas, legais, políticas, sexuais, etc.). A noção marxista de 'fetichismo da 
BORBA, J. Cultura política, ideologia e comportamento eleitoral:...

mercadoria' é exemplar nesse contexto: designa, não uma teoria (burguesa) da economia política, mas uma série de pressupostos que determinam a estrutura da própria prática econômica 'real' das trocas de mercado - na teoria, o capitalista agarra-se ao nominalismo utilitarista, mas, na prática (da troca, etc.), segue 'caprichos teológicos' e age como um idealista especulador. Por essa razão, a referência direta à coerção extra-ideológica (do mercado, por exemplo) é um gesto ideológico por excelência: o mercado e os meios de comunicação estão dialeticamente interligados; vivemos numa 'sociedade do espetáculo' (Guy Debord) em que a mídia estrutura antecipadamente nossa percepção da realidade e a torna indiscernível de sua imagem "esteticizada'" (ZIZEK, 1996, p. 20-21).

A ideologia "espontânea" seria próxima ao que Debrun denominou de ideologia primária, e que se está associando ao conceito de cultura política, ou seja, o momento de sua cristalização ou naturalização nas relações sociais. A importância destes conceitos é que eles permitem analisar a ideologia não só em suas grandes construções, expressas em "doutrinas" formuladas por "ideólogos", mas também a ideologia materializada em instituições ou em seu aspecto cotidiano, nas relações sociais.

Para o interesse deste trabalho, o fundamental é a percepção da relação dialética que existe entre a produção e emissão de conteúdos simbólicos (ideologias) e a recepção desses símbolos. As ideologias, ao mesmo tempo em que são constituídas pela cultura política de uma sociedade, acabam moldando esta mesma sociedade através da produção de novos significados que são internalizados nas práticas sociais.

Cabe agora analisar como os conceitos de cultura política e de ideologia podem servir como um referencial explicativo para o comportamento eleitoral.

O comportamento eleitoral e as tipologias do eleitor brasileiro

São várias as teorias que procuram explicar o comportamento eleitoral, e vários autores já fizeram a revisão desta literatura (CASTRO, 1992 e 1994; CARREIRÃO, 2000; RADMANN, 2001).

Dentre as principais correntes explicativas, podem-se destacar a perspectiva sociológica, a psicológica e a teoria da escolha racional (CASTRO, 1994). A perspectiva sociológica utiliza uma abordagem de tipo macro para explicar o comportamento político dos indivíduos, enfocando as condições sociais que constituem o contexto no qual as instituições, as práticas, as ideologias e os 
objetivos políticos se formam e atuam. O fundamental para a perspectiva sociológica é o contexto em que os indivíduos atuam, no qual as principais variáveis são as socioeconômicas, as demográficas e as ocupacionais, e sua preocupação central está em mostrar como tais variáveis possuem relações com o comportamento eleitoral.

Já as perspectivas psicológicas e psicossociológicas, que tiveram seu surgimento com o desenvolvimento e a disseminação das técnicas de survey nas ciências sociais e como principal núcleo acadêmico a Universidade de Michigan, buscaram interpretar o comportamento político a partir das motivações, percepções e atitudes dos indivíduos em relação ao mundo político. Estas abordagens não negam o impacto que fatores macroestruturais possuem sobre o comportamento eleitoral dos indivíduos, mas destacam que estes fatores somente não explicam tudo. Diante disso, salientam que o fundamental é pesquisar as opiniões, pois através delas pode-se prever a preferência dos indivíduos por um partido político que defendesse as mesmas idéias e prever qual seria sua atitude em termos de destino do voto (Cf. RADMANN, 2001, p. 23). Um clássico nesta área de estudos foi o livro The nature of belief systems in mass publics, de Philip Converse (1964), que demonstrou que os indivíduos se relacionam com o mundo político de acordo com seus níveis de conceituação deste mundo. Com base nesses níveis de conceituação formulou diferentes estratos de classificação, construindo uma tipologia para explicar o comportamento eleitoral ${ }^{8}$.

Por fim, existem as abordagens inspiradas pela teoria da escolha racional, que consideram a decisão do voto como produto de uma ação racional individual orientada por cálculos de interesse, que levam o eleitor a se comportar em relação ao voto como um consumidor no mercado. A esfera da política é visualizada como um "mercado político", onde os políticos tentam "vender seus produtos", e os cidadãos assumem o papel de "consumidores", que vão escolher aqueles "produtos" que melhor diminuam seus custos e maximizem ou otimizem seus ganhos 9 .

Os estudos de comportamento eleitoral no Brasil seguem os passos da literatura internacional, buscando a aplicação de um desses instrumentais ou a integração de diferentes paradigmas.

A preocupação da ciência política brasileira com o comportamento eleitoral data de meados dos anos 1950 com o trabalho pioneiro de Azis Simão sobre o voto operário em São Paulo. Nas décadas de 1960 e 1970, a ampliação dessa área de

\footnotetext{
8 Converse identifica cinco estratos de eleitores: os "ideólogos", os "!quase-ideólogos", o estrato do "interesse de grupo", o estrato "natureza dos tempos" e o estrato "sem conteúdo ideológico". Sobre o paradigma de Converse e sua aplicação no estudo do comportamento eleitoral no Brasil, ver Baquero (1985; 1994 e 2001).

${ }^{9}$ Referência neste tipo de abordagem encontra-se em Downs (1998).
} 
BORBA, J. Cultura política, ideologia e comportamento eleitoral:...

estudos deu-se com a publicação do clássico livro Sociedade e política no Brasil, de Gláucio Soares (1973), e as coletâneas organizadas por Bolivar Lamounier e Fernando Henrique Cardoso (1975), e Fábio Wanderley Reis (1978). Tais estudos utilizavam-se fortemente da explicação sociológica e psicossociológica para caracterizar o comportamento do eleitor brasileiro. A maioria destes trabalhos buscava analisar de que maneira fenômenos como a industrialização e a urbanização pelos quais o país vinha passando desde a década de 1930 tinham impacto sobre a forma dos cidadãos se relacionarem com a política; porém, nem todos se limitavam a isso, tendo alguns autores utilizado variáveis psicossociológicas na análise. Como destaca Castro,

“[...] a proposta não era negar a importância dos fatores macrosociológicos e da posição dos eleitores na estrutura social, mas ampliar a capacidade explicativa da teoria, incluindo as variáveis atitudinais e cognitivas na análise" (CASTRO, 1997, p. 151).

Mais recentemente, principalmente com o trabalho de Marcus Figueiredo (1991), as contribuições da teoria da escolha racional também foram incorporadas na análise do eleitor brasileiro.

O desenvolvimento deste campo de pesquisa permitiu que se formassem diferentes diagnósticos ou tipologias para a caracterização do voto no Brasil. Fábio Wanderley Reis, por exemplo, cunhou a expressão "síndrome do Flamengo" para caracterizar o voto da maioria do eleitorado brasileiro. Segundo Reis (2000a), as preferências partidárias ou ideológicas do brasileiro não se relacionariam com opiniões altamente sustentadas a respeito de questões de natureza política, mas estariam baseadas em imagens difusas, simplificadas da posição dos partidos: existiria no sistema de crenças da população uma divisão quase binária do processo político, de modo que os partidos estariam ou do lado do "povo" ou do "governo", dos "pobres" ou dos "ricos". Tal fenômeno faria com que o populismo fosse uma fatalidade na política brasileira. Nas palavras do autor:

"Assim, no eleitorado popular, em cuja percepção não se integram senão precariamente os diversos aspectos ou dimensões do universo sociopolítico, a opção eleitoral oposicionista parece ligar-se antes ao contraste vagamente apreendido entre o popular e o elitista ('pobres' versus 'ricos', 'povo' versus 'governo'), no qual se traduz uma insatisfação difusa incapaz de articular-se por referência a problemas específicos de qualquer natureza. Por outras palavras: votar na oposição é, para o eleitor em questão, um pouco como 'torcer' 
por um clube popular de futebol - o Flamengo, digamos, para tomar talvez o mais popular deles. Mas o simplismo mesmo das percepções e imagens em que se baseia essa propensão é um fator a emprestar consistência e estabilidade aos padrões de votação popular. Assentada a poeira das perturbações do quadro partidário, vislumbrados, em seguida a cada rearranjo mais ou menos artificial ou imposto desse quadro, os novos contornos político-partidários da contraposição entre 'povo' e 'elite', voltase, como no populismo do pré-64 e no MDB de pós-64, ao leito 'natural'. Temos, assim, uma espécie de 'síndrome do Flamengo' que não apenas tende a negar a um regime autoritário como o que controlou o país até 1985 a possibilidade de verdadeira legitimação pela via eleitoral como também faz do populismo, na atualidade brasileira, uma fatalidade, desde que as condições institucionais permitam um jogo político razoavelmente aberto e sensível perante o eleitorado". (REIS, 2000a, p. 78-79)

O trabalho de Castro (1994), diretamente influenciado pelo paradigma teórico de Reis ${ }^{10}$, procura explicar os mecanismos de decisão do voto segundo o grau de sofisticação política dos eleitores ${ }^{11}$. Segundo a autora, a sofisticação política seria a variável explicativa que melhor caracterizaria o comportamento eleitoral do brasileiro. Sua tese é que enquanto os eleitores sofisticados (minoria) votam orientados por opiniões sobre issues diversos e por uma preferência partidária baseada em uma visão informada sobre os partidos e os candidatos, a grande massa popular é desinformada e não tem opinião sobre as grandes questões do debate político, além do que, "[...] tende a atribuir a seus candidatos as qualidades que mais the agradam e as opiniões que eventualmente tem quanto a issues diversos e possui baixo grau de consistência ideológica" (CASTRO, 1994, p. 180).

Dessa forma, o voto da grande maioria do eleitorado orientar-se-ia através das "imagens" dos candidatos, que seriam "difusas" e "vagas", porém não totalmente imprevisíveis e aleatórias, pois, assim como Reis, a autora defende a tese de que o eleitor não sofisticado votaria, em grande parte, no candidato que the consegue transmitir a "imagem" de defensor privilegiado dos "pobres", dos "trabalhadores", da "maioria da população".

\footnotetext{
10 F. W. Reis busca, em seus trabalhos, uma integração entre as abordagens da teoria da escolha racional e da sociologia tradicional. No campo do comportamento eleitoral, propõe a inclusão de diversas abordagens no mesmo modelo teórico, integrando as perspectivas sociológica, psicológica e a teoria da escolha racional.

${ }^{11} \mathrm{O}$ grau de sofisticação política é constituído a partir do somatório de quatro variáveis: o interesse por política, o envolvimento no processo eleitoral, a exposição ao programa eleitoral gratuito na televisão e o grau de informação a respeito dos candidatos a presidente da república.
} 
BORBA, J. Cultura política, ideologia e comportamento eleitoral:...

Na mesma direção dos trabalhos que postulam o papel central da imagem dos candidatos no processo de decisão do eleitor, há o trabalho de Silveira (1998), embora para este autor o novo cenário político da mídia e do marketing produzam um "novo eleitor intuitivo e não racional".

Os estudos de Marcello Baquero, fortemente influenciados pela tradição da cultura política, identificam no Brasil um tipo de eleitor personalista e pragmático, marcado por fenômenos como o descrédito e a desconfiança em relação à política e aos políticos (BAQUERO, 1994), além de um forte sentimento de ineficácia política (BAQUERO e CASTRO, 1996). Tais fenômenos conduziriam a uma cultura política fragmentada e cética, sendo o personalismo "eleitoral" a conseqüência maior deste processo:

"[...] as atitudes de desconfiança e desencanto com as instituições, particularmente com os partidos, se dão num sentido de desvalorização concreta dessas instituições, gerando uma cultura política claramente personalista no sentido estrutural" (BAQUERO, 2000, p. 149).

Em trabalhos dedicados à aplicação do paradigma de Converse, Baquero (1985; 1994) identificou que a grande maioria dos eleitores da cidade de Porto Alegre (68,6 \% em 1982, 65\% em 1986, 57\% em 1988 e 1989, e 58,7\% em 1994) localiza-se nas escalas "natureza dos tempos" ou "sem conteúdo ideológico". Isso significa que a maioria dos eleitores consegue estabelecer pouquíssimas avaliações minimamente coerentes sobre fenômenos diversos da vida política.

Diante desse diagnóstico, e partindo do pressuposto que o contexto político influencia a decisão do voto, o autor, analisando as eleições de 1996 em Porto Alegre, afirma que o crescimento eleitoral do Partido dos Trabalhadores não significaria um realinhamento partidário ou ideológico por parte dos eleitores e sim uma avaliação do eleitor em relação à ação administrativa dos governantes (BAQUERO, 1997) ${ }^{12}$. O comportamento da maioria do eleitorado estaria guiado mais por critérios de eficiência na administração pública ou por questões "pósmaterialistas", como meio ambiente ou qualidade de vida, do que pela identificação ideológica. Apesar das diferenças em relação aos estudos abordados anteriormente, os trabalhos de Baquero também parecem indicar a valorização da imagem do candidato como aspecto da decisão do voto, estruturada a partir da valorização de atributos pragmáticos, como a competência administrativa.

\footnotetext{
12 A tese do voto personalista e pragmático também vem sendo adotada por Radmann (2001) e Borges (2001).
} 
Por sua vez, Singer (2000) defendeu tese polêmica sobre o comportamento do eleitor brasileiro segundo a qual a identificação ideológica deve ser incorporada à análise do comportamento eleitoral por ser um dos componentes de orientação do sufrágio e uma forte variável preditiva.

Para o autor, o eleitor possui um conhecimento abstrato do significado de esquerda e direita que lhe possibilita o posicionamento na escala ideológica, o qual, mesmo desestruturado, reflete o seu sistema de crenças. Singer aponta um uso intuitivo das categorias ideológicas esquerda/direita, que poderia ser caracterizado como um sentimento ideológico que "[...] permite ao eleitor colocar-se na escala em uma posição que está de acordo com suas inclinações, embora não saiba verbalizar. E a mesma intuição o conduz a situar os candidatos (e os partidos) nessa escala e votar coerentemente" (SINGER, 2000, p. 149).

Apesar deste uso intuitivo e não cognitivamente estruturado ${ }^{13}$, ao analisar as eleições de 1989 e 1994, o autor afirma que a parcela do eleitorado que se localizou na escala ideológica tendeu a votar coerentemente com seu autoposicionamento e não de modo indiferenciado.

Por fim, Carreirão (2000), ao analisar as eleições presidenciais de 1989, 1994 e 1998, postula que para dar conta dos diferentes critérios envolvidos na decisão do voto, um modelo deve incorporar pelo menos as seguintes variáveis como determinantes: a imagem política que o eleitor tem dos candidatos e partidos; a avaliação do eleitor sobre o desempenho do governo (presidente) em exercício; a avaliação do eleitor sobre algumas características pessoais dos candidatos em disputa, especialmente àquelas relativas à capacidade de governar e ao grau de escolaridade. Nesse sentido, a escolaridade seria uma variável interveniente, juntamente com os contextos eleitorais. Em sua análise, o autor afirma que a identificação ideológica, apesar de ser uma variável relevante, é mais comum entre os eleitores de alta escolaridade do que entre os de baixa escolaridade. Entre esses, que constituem a maioria do eleitorado, o autor conclui que parecem ter mais importância as avaliações que os eleitores fazem do desempenho do governo e das características pessoais do candidato.

\footnotetext{
${ }^{13}$ Segundo os dados de Singer, $60 \%$ dos entrevistados não sabem definir o que é esquerda ou direita. A identificação ideológica é definida através da auto-localização dos eleitores no contínuo esquerda/direita (a partir de respostas de surveys).
} 
BORBA, J. Cultura política, ideologia e comportamento eleitoral:...

As relações entre cultura política, ideologia e comportamento eleitoral no Brasil

Apesar das diferenças teóricas entre os autores, nesta revisão das tipologias sobre o comportamento eleitoral do brasileiro observa-se um certo consenso sobre algumas questões básicas, que são fundamentais nesta análise. O que se busca nesta seção é construir, a partir desta literatura, um marco analítico para abordar o comportamento eleitoral e sua relação com a cultura política e a ideologia.

Em primeiro lugar, a literatura analisada acima é consensual quanto ao baixo grau de informação e ao caráter difuso e pouco estruturado das opiniões políticas da maioria do eleitorado brasileiro. Isto não significa, no entanto, que existe a necessidade de visualizar o comportamento do eleitor brasileiro, como não racional (SILVEIRA, 1998). Como destaca Castro, o comportamento do eleitor brasileiro pode "[...] não corresponder ao cidadão ideologicamente orientado deduzido dos modelos clássicos de política democrática, ou à imagem, até certo ponto idealizada, do eleitor médio europeu, politicamente consciente" (CASTRO, 1997, p. 166), no entanto, seu voto expressa uma racionalidade que está estruturada a partir do nível cognitivo da grande maioria do eleitorado brasileiro e que se baseia em "imagens fluidas e difusas" a respeito dos políticos e dos partidos.

Em segundo lugar observa-se que a decisão do voto, para a grande maioria do eleitorado, está fortemente estruturada pelas "imagens políticas" e avaliações que o eleitor faz de algumas características pessoais dos candidatos em disputa. Apesar das análises de Singer (2000) indicarem que a identificação ideológica é um forte preditor do voto, percebe-se que ela está presente numa parcela mínima do eleitorado. Além disso, a forma como Singer elabora seu conceito de identificação ideológica, a qual significaria um "sentimento ideológico", não contraria, e sim reforça a tese de um voto a partir de "imagens".

Para os fins analíticos deste trabalho, acredita-se que não seja necessário estabelecer uma diferenciação rígida entre "imagens" políticas e "atributos" mais valorizados, como fazem alguns autores (CARREIRÃO, 2000). Quando se fala em imagem, não se faz referência somente ao posicionamento do eleitor em uma escala (por exemplo: esquerda/direita), ou em relação a determinadas prioridades (interesses do povo $\mathrm{x}$ interesses da elite), mas também a alguns atributos mais valorizados pelos eleitores na decisão do voto. A identificação com imagens políticas, de forma partidária, que no período bipartidário da política brasileira estruturavam-se fortemente entre as idéias de "partido do povo" e "partido do governo" ou entre "partido dos pobres" e "partido dos ricos", no contexto pluripartidário pós-1979 estruturavam-se principalmente através das imagens do candidato a partir de atributos como competência e honestidade. 
"Dentre os atributos mais valorizados pelos eleitores, a literatura vem destacando um menor peso para as imagens (candidato do povo/candidato da elite, esquerda/ direita) e dando maior ênfase para atributos como honestidade/integridade e a competência/ bom desempenho administrativo" (SILVEIRA, 1998, CARREIRÃO, 2000) $)^{14}$.

Com base nesses elementos, as possíveis relações estabelecidas entre a tipologia do eleitor brasileiro e os fenômenos da cultura política e da ideologia permitem investigar as causas do comportamento da grande maioria do eleitorado brasileiro, que decide seu voto, em grande parte, a partir de atributos pessoais do candidato, como a competência e a honestidade.

Cabe destacar, em primeiro lugar, que a personalização da política parece ser um fenômeno universal das democracias contemporâneas. 0 impacto dos meios de comunicação, que estabelecem uma relação direta entre representantes e representados, sem a necessidade de instituições de mediação política, como os partidos, e a conseqüente crise das identidades políticas tradicionais, vem provocando o surgimento de um novo tipo de governo representativo, denominado de "democracia do público" (MANIN, 1995). Neste tipo de democracia, o personalismo talvez seja o fenômeno mais observável. Como destaca Manin:

"[...] há muito tempo os analistas vêm constatando uma tendência à personalização do poder nos países democráticos. Nos países em que o chefe do poder executivo é eleito diretamente por sufrágio universal, a escolha do presidente da república tende a ser a eleição mais importante. Nos regimes parlamentaristas, onde o chefe do poder executivo também é o líder da maioria parlamentar, as campanhas e as eleições legislativas se concentram em torno da pessoa desse líder. Os partidos continuam a exercer um papel essencial, mas tendem a se tornar instrumentos a serviço de um líder. Ao contrário do que acontece na representação parlamentarista, é o chefe do governo, e não o membro do parlamento, que se considera como o representante por excelência. Contudo, da mesma maneira que acontece no parlamentarismo, a relação de representação tem um caráter essencialmente pessoal”. (MANIN, 1995, p. 25)

\footnotetext{
${ }^{14}$ Apesar de ressaltarmos a variável imagem/ atributo, isso não significa que propomos um modelo de análise do comportamento eleitoral. Isso implicaria a introdução de outras variáveis orientadoras do voto, como o voto por avaliação de desempenho (CARREIRÃO, 2000), o voto ideológico (SINGER, 2000), além de variáveis intervenientes, como o grau de sofisticação política do eleitorado (CASTRO, 1994).
} 
BORBA, J. Cultura política, ideologia e comportamento eleitoral:...

Mesmo que se concorde com a afirmação de um processo de personalização "universal" da política, este conceito deve ser no mínimo matizado quando são estabelecidas comparações entre países com democracias estáveis e países recém. democratizados e, com democracias que convivem com uma instabilidade crônica. A generalização, nesses casos, pode levar a erros graves na análise dos processos políticos recentes, como o que cometeu Novaro (1995a e 1995b), quando analisou o fenômeno do "menemismo" na Argentina (e se poderia acrescentar Collor no Brasil e Fujimori no Peru) como parte deste processo universal da democracia contemporânea. Em última instância, seguindo a análise de Novaro, pouca diferença (ou nenhuma) haveria entre a eleição de Menem na Argentina e Bill Clinton nos Estados Unidos, pois os dois países estariam vivenciando um processo de personalização da política.

Ora, se uma das opções metodológicas da política comparada é aquela que busca encontrar similaridades entre os fenômenos políticos, entende-se que esta busca não deve ser "cega", sob o risco de atribuir o mesmo significado a fenômenos diferentes. Assim, enquanto a personalização parece ser uma exceção e um fenômeno recente das democracias avançadas, em países como o Brasil ela sempre se constituiu em uma das regras do comportamento eleitoral. Além disso, nas democracias avançadas tal fenômeno convive com eleitores com níveis de sofisticação, estruturação ideológica e capacidade de conceitualização política muito superiores à média do eleitor brasileiro. Diante destes fatos, a explicação para o personalismo do eleitor brasileiro e a estruturação do voto guiada por atributos e imagens deve ser buscada na história do país e no seu impacto na conformação dos principais aspectos da sua cultura política.

Vários caminhos podem ser tomados na tentativa de compreender a história política brasileira. Em trabalhos anteriores apontei para o impacto que as idéias tecnocráticas e autoritárias tiveram, na configuração das estruturas do aparelho de Estado e da cultura política brasileira (BORBA, 2001, 2002 e 2003). Os dois regimes autoritários ao longo da história republicana foram fortemente racionalizados e legitimados por argumentos de inspiração tecnocrática, fazendo com que a organização do aparelho de Estado fosse fortemente estruturada a partir dessas idéias (como, por exemplo, nos conselhos técnicos), juntamente com a promoção de um forte desprestígio das instituições políticas constituintes da democracia, como o parlamento e os partidos políticos ${ }^{15}$. As conseqüências desses processos sobre estas instituições foram muitas, e dentre elas cabe destacar a estruturação de um sistema partidário extremamente fragmentado, instável,

\footnotetext{
${ }^{15}$ Sobre o impacto que essas idéias tiveram na estruturação dos partidos políticos na América Latina, ver o trabalho de Baquero (2000, cap. 2). Especificamente sobre o caso brasileiro, também há o clássico trabalho de Maria do Carmo Campello e Souza (1990 [1976])
} 
oligarquizado e extremamente frágil como mediador político entre a sociedade e o Estado. Diretamente relacionado com a fragilidade do sistema partidário, o poder legislativo caracterizou-se por uma permanente atrofia que, historicamente, o colocou a reboque de um poder executivo "todo poderoso".

Estes fatos, juntamente com vários aspectos da estrutura econômica da sociedade brasileira, na qual uma boa parcela dos seus cidadãos não tem acesso às mínimas condições para sua subsistência, foram em grande parte responsáveis pela configuração do sistema de crenças políticas da sociedade ${ }^{16}$. Deste modo, a conjugação de cidadãos pouco sofisticados com a constante difusão de ideologias antidemocráticas foi o elemento central da formação da cultura política brasileira, permitindo que o personalismo constituísse a base histórica de estruturação do comportamento eleitoral.

\section{Referências Bibliográficas}

ALMOND, G.; VERBA, S. The civic culture: political attitudes and democracy in five nations. Princeton: Princeton University Press, 1989 [1963].

ALMOND, G. The intelectual history of the civic culture. In: ALMOND, G.; VERBA, S. (Eds.) The civic culture revisited. Boston: Little, Brown and Company, 1980, p. 1-37.

ALTHUSSER, L. Ideologia e aparelhos ideológicos do Estado. In: ZIZEK, S. Um mapa da ideologia. Rio de Janeiro: Contraponto, 1996.

BADIE, B. ; HERMET, G. Culture et politique. Paris: Economica, 1993.

BAQUERO, M. Paradigma de Converse: sistemas de crenças e o processo eleitoral em 1982 em Porto Alegre-RS. Revista do Instituto de Filosofia e Ciências Humanas, v. 13, 1985.

. Os desafios na construção de uma cultura política democrática na América Latina: estado e partidos políticos. In: BAQUERO, M. Cultura política e democracia: os desafios das sociedades contemporâneas. Porto Alegre: Ed. da UFRGS, 1994. p. 26-41.

Novos padrões de comportamento eleitoral: pragmatismo nas eleições municipais de 1996 em Porto Alegre. In: BAQUERO, M. (Org.). A Lógica do processo eleitoral em tempos modernos: novas perspectivas de análise. Porto Alegre: Ed. Universidade/UFRGS; Canoas: Centro Educacional La Salle de Ensino Superior, 1997.

\footnotetext{
16 Para uma análise dos dados sobre a cultura política brasileira nos anos noventa, ver Moisés (1995), Castro (2000), Borba (2002).
} 
BORBA, J. Cultura política, ideologia e comportamento eleitoral:...

. A desconfiança como fator de instabilidade política na América Latina. In: BAQUERO, M.; CASTRO, H. C. de O.; GONZÁLES, R. S. (Orgs.). A construção da democracia na América Latina: estabilidade democrática, processos eleitorais, cidadania e cultura política. Porto Alegre: Ed. Universidade/UFRGS; Canoas: Centro Educacional La Salle de Ensino Superior, 1998.

Partidos e cultura política na América Latina: uma combinação de instabilidade política? In: BAQUERO, M. (Org.). Desafios da democratização na América Latina: debates sobre cltura política. Porto Alegre: Ed. Universidade/UFRGS; Canoas: Centro Educacional La Salle de Ensino Superior, 1999.

. A vulnerabilidade dos partidos políticos e a crise da democracia na América Latina. Porto Alegre: Ed. Universidade/UFRGS, 2000.

. Democracia, cultura e comportamento eleitoral: uma análise da situação brasileira. Paper apresentado no Seminário: Democracia: teoria e prática. Universidade Federal do Paraná. Curitiba, 20-22 de setembro de 2001.

BAQUERO, M.; CASTRO, H. C. de O. A erosão das bases democráticas: um estudo de cultura política. In: BAQUERO, M. (Org.). Condicionantes da consolidação democrática: ética, mídia e cultura política. Porto Alegre: Ed. Universidade /UFRGS, 1996.

BARRY, B. Los sociólogos, los economistas y la democracia. Buenos Aires: Amorrortu, 1970.

BORBA, J. O tecnocratismo como ideologia e instituição na sociedade brasileira. Paper apresentado no Seminário Internacional de Ciência Política, Porto Alegre, UFRGS, 2001.

Ideologia tecnocrática e cultura política no Brasil: o Plano Real e as eleições de 1994. Tese de doutorado, Programa de Pós-Graduação em Ciência Política, UFRGS. Porto Alegre, 2002.

. Ideologia tecnocrática e cultura política no Brasil. Paper apresentado no Colóquio Internacional "Políticas Públicas, Pobreza e Exclusão Social", Ujuí, novembro de 2003.

BORGES, P. E. A. Candidato ou partido? Avanços do voto pragmático no Brasil. Paper apresentado no Seminário Internacional de Ciência Política, Porto Alegre, UFRGS, 2001.

CARREIRÃO, Y. de S. A decisão do voto nas eleições presidenciais no Brasil (1989 a 1998): a importância do voto por avaliação de desempenho. Tese de doutorado em Ciência Política, USP, São Paulo, 2000.

. Identificação ideológica e voto para presidente. Paper apresentado no Seminário internacional de ciência política. Porto Alegre, UFRGS, 2001. 
CASTRO, H. C. de O. Democracia e mudanças econômicas no Brasil, Argentina e Chile: um estudo comparativo de cultura política. Tese de doutorado, Programa de Pós-Graduação em Ciência Política, Universidade Federal do Rio Grande do Sul. Porto Alegre, 2000.

CASTRO, M. M. Sujeito e estruturas do comportamento eleitoral. Revista Brasileira de Ciências Sociais, n. 20, 1992.

Determinantes do comportamento eleitoral: a centralidade da sofisticação política. Tese de Doutorado em Ciência Política, IUPERJ, Rio de Janeiro, 1994.

O comportamento eleitoral no Brasil: diagnóstico e interpretações. Revista Teoria \& Sociedade. UFMG, n. 1, p. 126-168, 1997.

CHILCOTE, R. Teorias de política comparativa: a busca de um paradigma reconsiderado. Petrópolis: Vozes, 1998.

CONVERSE, P. E. The nature of belief systems in mass publics. In: APTER, D. E. (Ed.). Ideology and discontent. New York: The Frie Press, 1964.

DIAMOND, L. (Ed.). Political culture and democracy in developing countries. Boulder: Lynne Rienner Publishers, 1994.

DEBRUN, M. A conciliação e outras estratégias. São Paulo: Brasiliense, 1983.

A ocultação ideológica: da "ideologia primária" à "ideologia secundária". In: DASCAL, M. Conhecimento, linguagem, ideologia. São Paulo: Perspectiva; EDUSP, 1989.

DOWNS, A. Uma teoria econômica da democracia. São Paulo: EDUSP, 1998.

EASTON, D. Uma teoria de análise política. Rio de Janeiro: Zahar, 1968.

FIGUEIREDO, M. A decisão do voto: (democracia e racionalidade). São Paulo: Ed. Sumaré; Anpocs, 1991.

. Teorias axiomáticas e empiria. Revista Brasileira de Ciências Sociais, n. 20, 1992.

INGLEHART, R. The renaissance of political culture. American Political Science Review, v. 82, n. 4. p. 1203-1229, 1998. 
BORBA, J. Cultura política, ideologia e comportamento eleitoral:...

. Cultura e democracia. In: HARRISOM, L.; HUNTINGTON, S. A cultura importa: os valores que definem o progresso humano. Rio de Janeiro: Record, 2002.

KRISCHKE, P. Cultura política e escolha racional na América Latina: interface nos estudos de democratização. BIB, n. 43, p. 103-126, $1^{\circ}$ semestre, 1997.

LAMOUNIER, B.; CARDOSO, F. H. (Orgs.). Os partidos e as eleições no Brasil. São Paulo: Cebrap; Paz e Terra, 1978.

LAMOUNIER, B.; SOUZA, A. Democracia e reforma institucional no Brasil: uma cultura política em mudança. Dados, v. 34, n. 3, 1991.

LANE, R. Political culture: residual category or general theory?. Comparative Political Studies, v. 25, n. 3, p. 362-387, 1992.

MANIN, B. As metamorfoses do governo representativo. Revista Brasileira de Ciências Sociais, ano 10, n. 29, 1995.

MOISÉS, J. A. Os brasileiros e a democracia. São Paulo: Ática, 1995.

NOVARO, M. Crisis de representación, neopopulismo y consolidación democrática. Sociedad, n. 6, abr, 1995a. out, 1995b.

O debate contemporâneo sobre a representação política. Novos Estudos Cebrap, n. 31,

PALMEIRA, M. Voto: racionalidade ou significado. Revista Brasileira de Ciências Sociais, n. 20, 1992.

PHARR, S. J.; PUTNAM, R. Disafected democracies: what's troubling the trilateral countries? Princeton: Princeton University Press, 2000.

PRZEWORSKI, A.; CHEIBUB, J. A.; LIMONGI, F. Democracia e cultura: uma visão não culturalista. Lua Nova, n. 58, p. 9-35, 2003.

PUTNAM, R. Comunidade e democracia: a experiência da Itália moderna. Rio de Janeiro: FGV, 1996.

RADMANN, E. R. O eleitor brasileiro: uma análise do comportamento eleitoral. Dissertação (mestrado em Ciência Política), Universidade Federal do Rio Grande do Sul. Porto Alegre, 2001. 
REIS, F. W. (Org.). Os partidos e o regime: a lógica do processo eleitoral brasileiro. São Paulo: Símbolo, 1978.

. Mercado e utopia: teoria política e sociedade brasileira. São Paulo: EDUSP, 2000.

Política e racionalidade: problemas de teoria e método de uma Sociologia crítica da política. Belo Horizonte: Ed. UFMG, 2000b.

RENNÓ, L. Teoria da cultura política: vícios e virtudes. BIB, Rio de Janeiro, n. 45, p. 71-92, 1. semestre de 1998.

SANTOS, W. Paradoxos do voto. Revista Brasileira de Ciências Sociais, n. 20, 1992.

SILVEIRA, F. E. A decisão do voto no Brasil. Porto Alegre: EDIPUCRS, 1998.

SINGER, A. Esquerda e direita no eleitorado brasileiro: a identificação ideológica nas disputas presidenciais de 1989 a 1994. São Paulo: EDUSP, 2000.

SOARES, G. A. D. Sociedade e política no Brasil (desenvolvimento, classe e política durante a Segunda República). São Paulo: Difusão Européia do Livro, 1973.

SOUZA, M. C. C. C. Estado e partidos políticos no Brasil (1930-1964). São Paulo: Alfa-Ômega, 1976 [1990].

STREET, J. Review article: political culture - from civic culture to mass culture. British Journal of Political Science, v. 24, p. 95-114, 1993.

THOMPSOM, J. Ideologia e cultura moderna: Teoria social crítica na era dos meios de comunicação de massa. Petrópolis: Vozes, 1995.

ZIZEK, S. O espectro da ideologia. In: ZIZEK, S. Um mapa da ideologia. Rio de Janeiro: Contraponto, 1996. 